УДК 327

DOI: http://dx.doi.org/10.15211/vestnikieran320211523

\title{
Пюбовь ШИШЕЛИНА
}

\section{ВЕНГРИЯ ВО ГЛАВЕ СОВЕТА ЕВРОПЫ}

\begin{abstract}
Аннотация. В статье анализируется программа председательства Венгрии в Комитете министров Совета Европь, органа, объединяющего сегодня 47 стран континента. Ньнешнее, уже второе председательство Будапешта в этой представительной европейской организации, как и первый раз, приходится на непростое время с точки зрения, как международной обстановки, так и мировой ситуачии с коронакризисом. Параллельно Венгрия будет председательствовать и в Вишеградской группе. А с учётом аналогичного статуса Словении в Совете ЕС с июля 2021 г. можно говорить о времени Центральной Европь в континентальной политике. Существенных перемен в этой связи ожидать не приходится, но странь региона попытаются акцентировать внимание всех на волнующих их проблемах. Отмечая характерное для Венгрии стремление вынести на международное обсуждение проблему начиональных меньшинств, автор одновре́менно подчёркивает желание Будапешта, удачно поддерживающего контакть и на восточном, и на западном направлении, содействовать урегулированию новых и старых кризисов, которые накопились в отношениях между Востоком и Западом.
\end{abstract}

Ключевые слова: Венгрия, Совет Европы, Программа председательства, пандемия, вакцинация, Центральная Европа.

С 21 мая до 17 ноября 2021 г. Венгрия возглавляет Комитет министров Совета Европы. С 1 июня она на год стала председателем Вишеградской группы. В то же время Совет ЕС возглавляет Словения. Таким образом, в высших европейских инстанциях вторая половина 2021 г. станет в полном смысле слова «центральноевропейской», а это значит - пронизана критической атмосферой ко многим инициативам Брюсселя, с учётом позиций в первую очередь Венгрии, а также в немалой степени Словении. Тем не менее революций ожидать не стоит, поскольку обычно, оказавшись во главе европейских структур, где ещё существует и «тройственный совет», центральноевропейские страны стараются следовать традициям и основным принципам организации. Однако одновре́менно они всё же пытаются продвинуть и свои интересы.

Председательство в Совете Европы перешло к Венгрии от Германии. На пост председателя Комитета министров этой организации Венгрия заступает во второй раз со времени её присоединения к этой организации 6 ноября 1990 г. в качестве 24-го члена СЕ.

\section{Надежды и разочарования первого председательства}

В первый раз Венгрия возглавляла СЕ в 1999 г., когда он отмечал своё 50-летие. Как го-

\footnotetext{
(C) Шишелина Любовь Николаевна - доктор исторических наук, главный научный сотрудник, руководитель Отдела исследований Центральной и Восточной Европы ИЕ РАН; профессор кафедры зарубежного регионоведения и внешней политики РГГУ. Адрес: 125009, Россия, Москва, ул. Моховая, д. 11, стр. 3. E-mail: 1.shishelina@gmail.com. ORCID: 0000-0002-8521-9225

Статья поступила в редакциию: 21.06.2021.
} 
ворится в новой программе её председательства, «спустя 22 года после принятия "Будапештской декларации о Большой Европе без разделительных линий” на 104-й сессии Комитета министров 7 мая 1999 г. Венгрия по-прежнему считает, что СЕ является выдающимся политическим институтом, способным объединить на равной основе и в постоянных структурах все страны Большой Европы» ${ }^{1}$. Будапештская декларация стала действительно значимым документом, появившимся в весьма драматичный для континента момент ${ }^{2}-$ на фоне Балканской войны - и в весьма символичном месте, так как ещё за 10 лет до этого «никто не мог предположить, что Совет будет отмечать свой полувековой юбилей в мае под руководством Венгрии - председательствовавшей тогда в Комитете министров - в Будапеште, в географическом центре Европы, ещё недавно скрытом за железным занавесом» ${ }^{3}$.

Красивые декларации о будущем и о прошлом принимались в 1999 г. парламентской Ассамблеей СЕ и руководимым Венгрией Советом министров в условиях жёсткой конфронтации СЕ с российской делегацией, считавшей действия НАТО в Югославии непоправимой ошибкой. Как пишет автор книги о первом десятилетии Европы без границ французский дипломат Дени Юбер, «в этих обстоятельствах цель построения "Большой Европы без разделительных линий”, которую Совет поставил перед собой в преддверии 50-й годовщины, внезапно оказалась такой же далёкой - или почти такой же, как и десять лет назад» ${ }^{4}$

В официальном документе СЕ «Демократическая совесть Европы», распространённом к 50-летию этой организации, тем не менее подчёркивалась историческая важность момента. «Впервые в своей истории вся Европа объединена под одной крышей - Совета Европы. Его главная цель - гарантировать достоинство наций и граждан континента путём обеспечения уважения наших основополагающих ценностей: демократии, прав человека и верховенства закона. Этот процесс объединения, который в течение 40 лет ограничивался Западной Европой, распространился на весь континент с 1989 г., и в настоящее время охватывает 41 государство и около 800 млн человек. 50 лет сотрудничества на правительственном, парламентском, региональном и местном уровнях способствовали превращению опустошенного и разделённого континента в среду, в которой могут восторжествовать свобода и справедливость» 5 .

И далее слова, по прочтении которых трагизм сегодняшней международной ситуации становится ещё более ощутимым, поскольку вйдение европейского будущего на рубеже столетий, времён первого венгерского председательства, так драматично не совпадало с возникшими позднее реалиями: «В преддверии нового столетия Совет Европы полон решимости в полной мере воспользоваться возможностями, предоставляемыми этой Великой Европой демократии. В постоянных усилиях по поддержке идеалов и принципов, которые как никогда составляют наше общее наследие, Совет Европы расширит свою деятельность по содействию социальной сплочённости, солидарности, образованию в интересах демократии, культурного разнообразия, качества жизни, и будет решительно стремиться построить Европу граждан, подлинный “Совет европейцев”»". Такого Совета не получилось, и многие идеи так и остались на бумаге.

Открывая 26 апреля 1999 г. официальные торжества, Янош Мартони, в то время министр

\footnotetext{
${ }^{1}$ Priorities of the Hungarian Presidency of the Committee of Ministers of the Council of Europe (21 May - 17 November 2021). URL: https://oslo.mfa.gov.hu/eng/news/majus-21-en-kezdodik-az-europa-tanacs-miniszteri-bizottsaganakmagyar-elnoeksege\#: :text=The $\% 20$ priorities $\% 20$ of $\% 20$ the $\% 20$ six,to $\% 20$ prepare $\% 20$ for $\% 20$ future $\% 20$ challenges (дата обращения 20.06.2021).

${ }^{2}$ Huber D. A Decade Which Made History. The Council of Europe 1989-1999. Imapress, 1989.

${ }^{3}$ Ibid. P. 177.

${ }_{5}^{4}$ Ibid.

${ }^{5}$ Ibid.

${ }^{6}$ Ibid.
}

Научно-аналитический вестник ИЕ РАН, 2021, №3 
иностранных дел Венгрии и председатель Комитета министров СЕ, говорил об «основополагающем значении» этого события (единство континента), о «законной гордости» за проделанную работу, но также и о печали в связи с трагедией в Косово, которая «показывает (несмотря на необычайный прогресс, достигнутый за предшествовавшие 10 лет), что путь всё ещё долог, пока это европейское единство, которое Совет Европы призван воплотить в жизнь, не станет реальностью». Одновре́менно он говорил и о своей «вере в способность СЕ и его государств-членов построить будущее, которое будет лучше, чем прошлое. Косовская трагедия не является олицетворением будущего Европы; она ужасный продукт тех смертоносных сил агрессивного национализма, нетерпимости, политического экстремизма, которые погрузили наш континент в пропасть, где он оказался в 1945 г. Клятва, данная отцами - основателями Совета Европы “Никогда больше!” - продолжил Мартони, - должна оставаться нашим объединяющим лозунгом в построении Европы завтрашнего дня» ${ }^{1}$.

События тех дней выглядели хаотичными, поскольку в Югославии Европа столкнулась с неожиданной для неё реакцией поддержки населением президента Милошевича, а НАТО действовала в обход ООН и СЕ. Вряд ли в тех условиях голос накануне принятой в альянс Венгрии мог бы изменить ситуацию. Не понятно, как долго продлилась бы война и как выходила бы из неё Европа, если бы не позиция России и назначение В.С. Черномырдина специальным представителем президента Ельцина по югославскому урегулированию. Символично, что на фоне войны с юбилеем поздравляли СЕ из космоса россияне Виктор Афанасьев и Сергей Авдеев - члены экипажа 27-й миссии космической станции «Мир».

Много лет как нет и станции «Мир», а обстановка в целом балансирует сегодня, как сказал нынешний министр иностранных дел Венгрии Петер Сийярто, на грани холодной войны. Однако тот символичный жест, безусловно, стал хорошим фоном для принятия Будапештской декларации в большом философском смысле - вѝдения маленькой Земли из большого космоса. На встрече в Бонне 6 мая 1999 г. министры иностранных дел «большой восьмёрки», представляющие семь наиболее развитых промышленных стран и Россию, изложили «общие принципы», которые, по их мнению, могли бы привести к быстрому урегулированию балканского / европейского кризиса. За этим последовало энергичное возвращение России на дипломатическую арену в качестве центрального игрока в поисках политического решения конфликта. И, наконец, на 104-й сессии Комитета министров СЕ представители 41 государства-члена предприняли ряд решительных шагов по определению будущего Совета путём принятия «Будапештской декларации о Большой Европе без разделительных линий». В ней были определены четыре основные цели будущих действий Совета: стабильность европейского континента, которая должна была «основываться на демократических институтах» и включать выполнение «всех обязательств, которые давались государствами друг другу, Совету Европы и гражданам»; политическая, правовая, социальная и культурная сплочённость Большой Европы; главенство человеческой личности в европейской политике; общая приверженность демократии и верховенству закона, основанная на действиях по развитию существующего партнёрства между правительствами, парламентами, местными и региональными властями, гражданским обществом и различными международными организациями, которые помогали развивать и структурировать континент» ${ }^{2}$.

Сегодня, заступая на пост председателя в Комитете министров Совета Европы, Венгрия второй раз входит практически в те же воды, но уже обретя определённый опыт и междуна-

\footnotetext{
1 Official opening of the $50^{\text {th }}$ anniversary celebrations. Strasbourg, 26.04.1999, Palais de l'Europe. URL: https://rm.coe.int/0900001680534cf8 (дата обращения 27.06.2021).

${ }^{2}$ Huber D. Op. cit.
}

Научно-аналитический вестник ИЕ РАН, 2021, №3 
родный имидж «сопротивленца» централизованным директивам в рамках Европейского союза. Вновь на повестке сложные вопросы и европейской политики, и отношений с Россией, а также критического восприятия самой Венгрией нормотворческого процесса в ЕС. Сможет ли страна вновь внести запоминающийся вклад? Этот год, несмотря на новое обострение полемики в Брюсселе, всё же можно назвать «венгерским», поскольку одновре́менно с председательством в СЕ Будапешт будет возглавлять и Вишеградскую группу - организацию, существенно повысившую свой авторитет в Европе.

\section{Основные положения Программы 2021 года}

Второе председательство Венгрии выпало на не менее драматичный момент, когда мир вступил в один из важнейших этапов борьбы с пандемией COVID-19, на фоне серьёзных межгосударственных и глобальных противоречий, обновления элит, борьбы ценностных ориентиров.

Как говорится в Программе, подготовленной к председательству в СЕ, «Венгрия хотела бы воспользоваться возможностью содействовать укреплению культурного сообщества, сформированного Европой, обогащённой своим разнообразием, уверенной в своей самобытности и открытой миру. В дополнение к давним традиционным обязательствам Венгрия также хотела бы содействовать продолжающейся работе над нашими общими ответами на новые вызовы, с которыми сталкиваются современные общества...» ${ }^{1}$.

Будапешт выделил пять приоритетов, на которых хотел бы сосредоточиться: 1) содействие эффективной защите национальных меньшинств; 2) межрелигиозный диалог; 3) проблемы молодого поколения «Generation Next»: права детей, молодёжи, цыган; 4) технологические и 5) экологические вопросы.

Проблема национальных меньшинств актуальна для Венгрии со времён Трианонского договора 1920 г. Поэтому Будапешт всегда старается включать эту тему в свои международные акции. А в 2020 г. исполнилось 100 лет этой трагической для венгров дате. Как говорится в программном заявлении, Венгерское председательство хотело бы подчеркнуть важность эффективной защиты национальных меньшинств в Европе серией из пяти мероприятий, организованных в Страсбурге и Будапеште.

Так, тема первой конференции высокого уровня в конце июня в Страсбурге - освещение правовых стандартов Совета Европы в области защиты лиц, принадлежащих к национальным меньшинствам, и их языков. Её цель - как прописано в документе - состоит в том, чтобы оценить результаты, достигнутые к настоящему времени, в том числе благодаря реформам, начатым в 2018 г. под председательством Хорватии.

Второе мероприятие председательства в этой области направлено на изучение роли и вклада неправительственных организаций и исследовательских центров в защите национальных меньшинств.

Третьим значится совещание экспертов по изучению передовой практики двустороннего сотрудничества и функционирования моделей самоуправления в регионах Совета Европы.

Четвёртым станет ещё одна конференция с международным участием, посвящённая защите национальных меньшинств, проживающих в Венгрии, что даст возможность принять меры в связи с последними докладами о мониторинге в этой области.

И на заключительном пятом этапе планируется обсудить особую роль и ответственность Совета Европы, а также других международных организаций в вопросах, связанных с национальными меньшинствами. На форуме для политических лидеров и экспертов они смогут по-

\footnotetext{
${ }^{1}$ Priorities of the Hungarian Presidency...

Научно-аналитический вестник ИЕ РАН, 2021, №3
} 
делиться своими идеями и предложениями, на основе которых будет разработана декларация о перспективной политике в области защиты национальных меньшинств.

Венгрия уже внесла вклад в развитие проблематики национальных меньшинств в Совете Европы. Так, ей принадлежит решающая роль в принятии в 1992 г. Европейской хартии по защите региональных языков и языков национальных меньшинств ${ }^{1}$ и в 1995 г. рамочного Соглашения «О защите национальных меньшинств» ${ }^{2}$.

Религиозный аспект межкультурного диалога направлен на укрепление взаимного уважения, взаимопонимания и терпимости в европейском обществе на общеевропейском уровне. Как отмечается в Программе Венгрии, межконфессиональный диалог составлял важную часть ежегодного календаря Комитета министров с 2008 по 2017 гг. и рассматривался в ряде рекомендаций Парламентской ассамблеи Совета Европы. Венгерское председательство стремится придать новый импульс этим обсуждениям в сотрудничестве со специальным представителем генерального секретаря по вопросу об антисемитизме, антимусульманских и других формах религиозной нетерпимости и преступлениях на почве ненависти.

На полях четвёртой сессии Парламентской Ассамблеи Совета Европы планируется в сентябре провести мероприятие с участием соответствующих международных НПО, чтобы осветить проблемы предоставления гуманитарной помощи: как она конкретно распределяется между религиозными общинами. Деятельность на этом направлении должен увенчать симпозиум с участием государственных должностных лиц и религиозных лидеров для изучения проблемы религиозного плюрализма в отношении межкультурного взаимодействия и обсуждения общих ценностей, общей ответственности религий и конфессий, а также связанных с этим проблем XXI в.

Следующее поколение (Generation Next). К этому направлению венгерского Председательства отнесены вопросы защиты семейных ценностей, молодёжной политики, прав детей, а также социальной интеграции цыганского народа. Как отмечается в документе, глобальный кризис, вызванный пандемией COVID-19, и его экономические и социальные последствия негативно сказались на почти всех сторонах жизни всех групп общества. Для детей и молодёжи пандемия несёт значительные риски в области образования, занятости и психического здоровья. С учётом этого венгерское председательство проведёт ряд мероприятий, посвящённых воздействию пандемии на детей и молодёжь, уделив особое внимание уязвимым и обездоленным группам, таким как цыгане. Отмечается, что Венгрия в этих областях следует стратегии и планам действий Совета Европы, что подтверждает размещение Европейского молодёжного центра в Будапеште с 1995 г. $^{3}$

В 2020 г. центр отметил своё 25 -летие 4 . Предложение о создании такого молодёжного учреждения в «сердце» Европы было сделано ещё первым «постсоциалистическим» премьер-министром Венгрии Йожефом Анталлом в начале 1990-х (как вклад только что вступившей в Совет Венгрии) и принято Комитетом министров СЕ в 1993 г. В то время открытие молодёжного центра в Будапеште рассматривалось как символ падения «железного занавеса» и открытия нового будущего для молодёжи региона. Уже в мае 1999 г. во время председательства Венгрии и празднования 50-летия СЕ центром было организовано несколько торжествен-

\footnotetext{
1 Regionális vagy kisebbségi nyelvek európai chartája. URL: https://rm.coe.int/ecrml-educational-toolkit$\mathrm{hu} / 16809 \mathrm{a} 43 \mathrm{cb}$ (дата обращения 27.06.2021).

${ }^{2}$ Keretegezmény a nemzeti kissebbségek védelméröl. Európa Tanács. Strasbourg, 1994. URL: https://rm.coe.int/CoER MPublicCommonSearchServices/DisplayDCTMContent?documentId=09000016800c1308 (дата обращения 27.06.2021).

3 A Budapesti Európai Ifjúsági Központ első 25 éve. Council of Europe. URL: https://www.coe.int/en/web/youth/beik25 (дата обращения 27.06.2021). ${ }^{4}$ Ibid.
}

Научно-аналитический вестник ИЕ РАН, 2021, №3 
ных мероприятий для европейской молодёжи. С 2000 г. на базе центра действует молодёжная образовательная программа по правам человека для активистов и педагогов из стран региона. Её целью является «защита и продвижении основополагающих ценностей Совета Европы, она призвана играть ведущую роль в области образования, прав человека, в молодёжной политике и в практике работы с молодёжью по всей Европе, в том числе в Венгрии» ${ }^{1}$. Курс включает обучение по проблемам преодоления ненависти, антисемитизма или исламофобии, гомофобии, нарушения прав меньшинств. Он, как говорится в уставных документах, способствует диалогу, сотрудничеству между различными нациями и поддерживает усилия национальных меньшинств в Европе по сохранению их языка и культурной и региональной автономии ${ }^{2}$.

С 2003 г. на базе центра ежегодно организуется летний молодёжный лагерь. В 2011 г. здесь же открылась онлайн-школа для школьников «Движение против ненависти» (No hate speech movement), в которой принимают участие подростки из 45 стран. В 2015 г. Будапештский центр организовал вторую общеевропейскую конференцию цыганской молодёжи. Так что у Венгрии за три десятилетия членства в Совете Европы накопился достаточный опыт в этой сфере.

Пандемия, оказавшая значительное влияние на жизнь молодых людей, делает ещё актуальнее осуществление Стратегии молодёжного сектора Совета Европы до 2030 г. В этой связи венгерским председательством будет организован семинар под названием «Перезапуск, обновление, реинтеграция - возможности для молодёжи после коронавируса», который должен разработать рекомендации по поддержке и реинтеграции молодёжи в сфере занятости.

Социальной интеграции детей цыган будет посвящена конференция под названием «От рождения до трудоустройства». Одновре́менно в Будапеште пройдёт 4-е совещание Комитета экспертов по вопросам цыган и кочевников.

Венгерское председательство поддерживает работу Группы Помпиду и ожидает, что её проект пересмотренного устава будет принят Комитетом министров во время празднования 50-летия Группы в Париже.

Четвёртый и пятый пункты Программы Венгрии посвящены прикладным вопросам из сферы технологий и экологической политики.

Технологические вызовы в документе увязаны с правосудием в цифровую эпоху, искусственным интеллектом, борьбой с киберпреступностью. В октябре 2021 г. в Будапеште состоится конференция министров юстиции государств - членов Совета Европы. Как считают организаторы, обмен мнениями предоставит возможность обсудить достижения и проблемы, связанные с цифровизацией правосудия и применением искусственного интеллекта в судебных целях. Председательство будет содействовать дальнейшей разработке глобальной политики по регулированию проектирования и использования систем искусственного интеллекта, координируемой с другими международными организациями. В частности отмечается, что Венгрия поддерживает работу Специального комитета по искусственному интеллекту (CAHAI), которая должна быть завершена в конце 2021 г. Кроме того, окончание венгерского председательства совпадает с 20-летием Будапештской конвенции по киберпреступности. По этому случаю также запланированы торжества.

Среди тем, связанных с окружающей средой, Венгрия выбрала такие направления, как защита европейского ландшафта и среды обитания, устойчивое развитие. Под эгидой Венгерского председательства запланирована 11-я конференция по Европейской ландшафтной кон-

\footnotetext{
${ }^{1}$ Ibid.

${ }^{2}$ Ibid.
}

Научно-аналитический вестник ИЕ РАН, 2021, №3 
венции. Важным событием станет открытие Конвенции о ландшафте для неевропейских государств. Вопросам окружающей среды и прав человека, являющимся политическими приоритетами для Парламентской Ассамблеи, будет посвящена её Четвёртая сессия в 2021 г. На следующем Всемирном форуме за демократию в ноябре будут проведены дебаты по смежным темам и выработаны новые идеи для преодоления экологического кризиса, с которым Европа и мир сталкиваются сегодня.

\section{Намерения руководства Венгрии}

На церемонии приёма полномочий от министра иностранных дел Германии Хайко Мааса его венгерский коллега Петер Сийярто высказал надежду, что полгода председательства Венгрии позволят возобновить диалог «Восток - Запад»: «Существуют жёсткие конфликты между политическим Востоком и политическим Западом, и эта риторика уже напоминает холодную войну. В этом контексте способность Венгрии вести переговоры и на Востоке, и Западе, надеюсь, будет оценена по достоинству. Как председатель главного органа по принятию решений CE, который объединяет, как восточные, так и западные страны, надеюсь, что мы сможем обеспечить платформу для взаимного уважения и диалога, основанного на взаимном доверии» ${ }^{1}$. Не в последнюю очередь имелся в виду свежий российско-чешский конфликт, поскольку министр иностранных дел Чехии Якуб Кулханек встречался накануне, 12 мая, с венгерским коллегой ${ }^{2}$ и не мог обойти стороной проблемные отношения Праги и Москвы. Однако в Центральной Европе есть ещё государства, отношения которых с Москвой не внушают оптимизма и требуют хотя бы попытки коррекции.

Министр юстиции Венгрии Юдит Варга в своей беседе с Генеральным секретарем СЕ Марией Пейчинович-Бурич подчеркнула, что ключевым принципом шестимесячного венгерского председательства в Совете Европы станет уважение к национальным традициям ${ }^{3}$.

Из-за продолжающейся пандемии, даже несмотря на успех ряда стран в массовой вакцинации населения, Венгрия не сможет провести все запланированные мероприятия в очном формате, но приложит усилия, чтобы сделать их максимально результативными, заявил председатель комитета по международным делам Венгерского парламента Жолт Немет на встрече в Страсбурге с европейскими коллегами ${ }^{4}$.

Председательство - это не только честь, но и обязанность для страны обеспечить основу будущей деятельности СЕ с учётом приоритетов. 21 июня Венгрия внесла добровольное пожертвование на осуществление программ Совета Европы в размере 450 тыс. евро. Эти средства по договорённости сторон будут потрачены на следующие программы:

- план действий СЕ для Украины на 2018-2022 гг.;

- стратегический план действий СЕ по интеграции цыган и кочевников 2020-2025 гг.;

- защита детей от нарушения их прав;

- меры по борьбе с киберпреступностью;

- европейская ландшафтная конвенция;

\footnotetext{
${ }^{1}$ A magyar elnökség lehetőséget ad a kelet-nyugati párbeszédre. Magyar Nemzet. 21.05.2021. URL: https://magyarnem zet.hu/kulfold/a-magyar-elnokseg-lehetoseget-ad-a-kelet-nyugati-parbeszedre-9832136/ (дата обращения 20.06.2021).

2 Minister Kulhánek met with his counterpart in Budapest, the main topics were travel and the economy. Ministry of Foreign Affairs of the Czech republic. 12.05.2021. URL: https://www.mzv.cz/jnp/en/issues_and_press/press_releases/ x2021_05_12_minister_kulhanek_met_with_his.html (дата обращения 20.06.2021).

${ }^{3}$ Justice Minister Presents Hungary Upcoming Presidency Priorities, Programmes to CoE SecGen MTI-Hungary Today. 31.03.2021. URL: https://hungarytoday.hu/justice-minister-varga-hungary-upcoming-coe-presidency-priorities/ (дата обращения 20.06.2021).

4 Németh Zsolt: Az Európa Tanács magyar elnökségének prioritásai az ET támogatását élvezik/ Magyar Hirlap. 21.04.2021. URL: https://www.magyarhirlap.hu/kulfold/20210421-nemeth-zsolt-az-europa-tanacs-magyarelnoksegenek-prioritasai-az-et-tamogatasat-elvezik (дата обращения 20.06.2021).
}

Научно-аналитический вестник ИЕ РАН, 2021, №3 
- мероприятия в рамках Бернской конвенции;

- поддержка охраны окружающей среды и других новых методов управления проектами для сотрудничества;

- поддержка конкуренции в суде по спорным вопросам прав человека.

Для премьер-министра Виктора Орбана, как и для его соратника по партии ФИДЕС Ж. Немета, это уже второй опыт управления страной параллельно с председательством в Комитете министров Совета Европы. Данное обстоятельство на фоне накопившихся разногласий в $\mathrm{EC}$, идёт на пользу Будапешту, поскольку идеи, которые Венгрия пока не смогла провести в Европейском парламенте, она может попытаться реализовать или хотя бы озвучить на уровне Совета Европы. В целом же голос Центральной Европы становится всё более решительным, опыт всё более убедительным, что полезно принимать во внимание и Российской Федерации.

Венгрия уже во второй раз приступила к исполнению обязанностей председательствующего в Комитете министров Совета Европы, но, как и в первый, на её долю выпало весьма нелёгкое время, причём не только с точки зрения международных проблем, но и вследствие мировой пандемии. Планов много, и что характерно для Будапешта, - в приоритетах остаётся проблема национальных меньшинств в Европе. Проблема сложная, поскольку за 100 лет со времени появления, она так и не нашла приемлемого и устраивающего всех решения (если таковое возможно в принципе). Но очередная попытка найти развязку правовым и бесконфликтным путём не может не внушать оптимизма, когда на виду у всей Европы продолжают тлеть многочисленные неразрешённые конфликты на постсоветском пространстве. Хочется также надеяться, что при посредничестве Венгрии, удастся выйти на качественно новый уровень позитивных отношений Восток - Запад, Россия - Центральноевропейские страны.

\section{Список литературы}

Европа между трёх океанов / под ред. Ал.А. Громыко, В.П. Фёдорова. М.: ИЕ РАН, издательство «Весь мир», 2019.

Европейский союз в XXI веке: время испытаний / под ред. Н.Б. Кондратьевой. М.: ИЕ РАН, издательство «Весь мир», 2012.

Трансформационные революции в странах Центральной и Юго-Восточной Европы. К 30 летию событий. 1989-2019 / под ред. К.В. Никифорова. М.: Институт славяноведения РАН; СПб.: Нестор-История, 2021.

Центральная Европа: политический портрет на фоне 100-летия / под ред. Л.Н. Шишелиной, М.В. Ведерникова. М.: ИЕ РАН, 2018.

Шишелина Л.Н. Расширение Европейского союза на восток и интересы России. М.: Наука, 2006.

\section{References}

Gromyko, Al.A., Fedorov, V.P. (eds.) (2019). Evropa mezhdu trekh okeanov: monografiya [Europe between three oceans: monograph]. Moscow: IE RAS, Publishing house «Ves' mir».

Huber, D. (1989). A Decade Which Made History. The Council of Europe 1989-1999. Imapress.

Jensen, J., Miszlivetz, F. (2014). Reframing Europe's Future. Challenges and Failures of the European Construction. Routledge. 
Kiss, J.L. (2003). Globalizálodás és külpolitika. Budapest: TLA. (In Hungarian).

Kondrat'eva, N.B. (ed.) (2012). Evropeiskii soyuz v XXI veke: vremya ispytanii [EU in XXI century: time of challenges]. Moscow: IE RAS, Publishing house «Ves' mir».

Nikiforov, K.V. (ed.) (2021). Transformatsionnye revolyutsii v stranakh Tsentral'noi i YugoVostochnoi Evropy. K 30-letiyu sobytii. 1989-2019 [Transformational revolutions in the countries of Central and South-Eastern Europe on their thirtieth anniversary]. Moscow: Institute for Slavic studies RAS; Saint-Petersburg: Publishing house «Nestor-Istoriya».

Priorities of the Hungarian Presidency of the Committee of Ministers of the Council of Europe (21 May - 17 November 2021). Available at: https://oslo.mfa.gov.hu/eng/news/majus-21-en-kezdod ik-az-europa-tanacs-miniszteri-bizottsaganak-magyar-elnoeksege\#: :text=The\%20priorities\%20of $\% 20$ the\%20six,to\%20prepare\%20for\%20future\%20challenges (accessed 20.06.2021).

Shishelina, L. (2006). Rasshirenie Evropejskogo soyuza na vostok i interesy Rossii [Expansion of EU to East and Russian interests]. Moscow: Nauka.

Shishelina, L.N., Vedernikov M.V. (eds.) (2018). Central'naya Evropa: Politicheskij portret na fone 100-letiya [Central Europe: political portrait amidst $100^{\text {th }}$ anniversary]. M.: IE RAS. (In Russian).

\section{Hungary at the Head of the Council of Europe}

Author. Lyubov Shishelina, Doctor of Sciences (History), Head of the Department for Central and Eastern Europe, Institute of Europe, Russian Academy of Sciences; Professor, Department of Foreign and Regional Policy Studies, RSUH. Address: 11-3, Mokhovaya str., Moscow, Russia, 125009. E-mail: 1.shishelina@gmail.com. ORCID: 0000-0002-8521-9225

Abstract. In the article, the author analyzes the program and plans of Hungary's Presidency in the Council of Europe, a body that unites 47 countries of the continent today. This is the second presidency of Budapest in this representative European organization and, like the first time, it comes at a difficult time in terms of both the international situation and the global situation with the Coronacrisis and its consequences. The author notes that in parallel, Hungary will also chair the Visegrad Group. And taking into account the Slovenian presidency of the Council of the EU from July 2021, we can talk about the time of Central Europe in continental politics. The author notes that significant changes in this regard should not be expected, but the countries of the region will try to focus the attention of the whole of Europe on the issues of concern to Central Europe. Noting Hungary's characteristic desire to bring the issue of national minorities to international discussion, the author also emphasizes the desire of Budapest, which successfully maintains contacts both in the eastern and western directions, to help resolve the new and old crises that have accumulated in relations between the East and the West of Europe to this day.

Key words: Hungary, Council of Europe, Presidency Program, pandemic, vaccination, Central Europe.

DOI: http://dx.doi.org/10.15211/vestnikieran320211523 